\title{
Evacuación aeromédica de pacientes COVID-19. Reporte de casos
}

\section{Case reports: Aeromedical evacuation of patients COVID-19}

\author{
Max Wanner E. ${ }^{1,3}$, Gino La Rosa A. ${ }^{1,3}$, María Carolina Cabrera S. ${ }^{1,3}$,
}

Carlos Polanco L. ${ }^{1}$, Xabier De Aretxabala U. ${ }^{1,2}$

\begin{abstract}
Background: The aeromedical evacuation in the Chilean Air Force has had an important development in the last 15 years. The coronavirus disease declared as a global pandemic by the WHO has generated the challenge of transferring highly infectious patients to centers of greater complexity. The objective of this article is to report our experience in the transfer of COVID - 19 patients in constant attention and medical monitoring. Clinical case reports: The aeromedical evacuation of 2 COVID-19 patients was performed from the Hanga Roa Hospital, Rapa Nui, to the National Thorax Institute, Metropolitan Region, in a Lockheed Hercules C-130, which corresponds to a pressurized fixed-wing airplane. The transfer was carried out with the corresponding personal protection elements and in individual isolation capsules with advanced negative pressure life support (ISO - POD), in order to reduce the level of contagion to the aero sanitary crew and minimize the impact on the flight material used. Discussion: The transfer was carried out achieving all the objectives set out under a strict security protocol and the two COVID-19 patients were transferred successfully. The negative pressure isolation capsule system was safe and reliable, since no crew member presented symptoms or was infected by COVID -19 , and also allowed the transfer of highly contagious patients during an 8-hour flight operation.
\end{abstract}

\section{RESUMEN}

Introducción: La evacuación aeromédica en la Fuerza Aérea de Chile ha tenido un importante desarrollo en los últimos 15 años. La enfermedad por coro-

\section{Key words:}

Aeromedical evacuation, individual isolation capsules at negative pressure

\section{Palabras clave:}

Evacuación aeromédica, cápsulas de aislamiento individual a presión negativa

\footnotetext{
Hospital Clínico de la Fuerza Aérea de Chile.

Clínica Alemana.

Universidad de Valparaíso.
}

Fecha de recepción: 30042020

Fecha de aceptación: 30042020

\section{ORCID}

https://orcid.org/0000-0002-2682-0395

Correspondencia:

Dr. Max Wanner

Email: wanner3155@gmail.com 
navirus declarada como pandemia mundial por la OMS ha generado el desafío de trasladar pacientes altamente infecciosos a centros de mayor complejidad. El objetivo de este artículo es reportar nuestra experiencia en el traslado de pacientes COVID - 19 en constante atención y monitorización médica. Reporte de casos clínicos: Se realizó la evacuación aeromédica de 2 pacientes COVID - 19 desde el Hospital de Hanga Roa, Rapa Nui, hacía el Instituto Nacional del Tórax, Región Metropolitana, en un Lockheed Hércules C-130, que corresponde a un avión de ala fija presurizado. El traslado se realizó con los elementos de protección personal correspondientes y en capsulas de aislamiento individual con soporte vital avanzado a presión negativa (ISO - POD), con la finalidad de reducir el nivel de contagio a la tripulación aero sanitaria y minimizar el impacto en el material de vuelo utilizado. Discusión: El traslado se desarrolló logrando todos los objetivos planteados bajo un estricto protocolo de seguridad y los dos enfermos COVID-19 fueron trasladados de manera exitosa. El sistema de cápsulas de aislamiento a presión negativa fue seguro y confiable, ya que ningún miembro de la tripulación presento sintomatología o resultó contagiado por COVID -19, y además permitió trasladar pacientes altamente contagiosos durante una operación de vuelo de 8 horas.

\section{Introducción}

La Fuerza Aérea de Chile desde la década de los 80 , ha realizado múltiples evacuaciones aeromédicas a lo largo del territorio nacional. La definición de una evacuación aeromédica es el traslado de un paciente desde un lugar donde no se cuentan con los recursos necesarios para mantener su vida, destacando que es un traslado de cama a cama y que se encuentra bajo una visión médica continua. Esto significa mantener o elevar los cuidados del paciente durante el vuelo, por lo tanto, el traslado debe tener una sólida justificación y deben disponerse de los recursos necesarios para que el nivel de cuidado no decaiga durante el vuelo.

En el contexto actual del COVID - 19, la evacuación aeromédica de pacientes altamente contagiosos ha debido desarrollarse a nivel mundial y su propósito es trasladar pacientes que requieran un manejo en un centro de mayor complejidad tecnológica y experiencia técnica, además de profesionales especializados en el área de cuidados intensivos. Todo este traslado a cargo de personal médico calificado, ya que dentro de las características del cuadro causado por este, el compromiso del parénquima pulmonar exige la instalación de ventilación mecánica. Para este tipo de traslado se utilizaron cámaras de aislamiento individual con soporte vital avanzado (ISO - POD) y elementos de protección personal específicos, el uso de estos sistemas de encapsulamiento permite mejorar el nivel de protección física del personal encargado de la asistencia y transporte, a la vez que reduce el esfuerzo de desinfección del medio utilizado en el transporte una vez finalizado este, debido a que minimiza el riesgo de contaminación. Estos dispositivos disponen de presión negativa en su interior lo que les permite ser utilizados para el transporte de pacientes donde el peligro se encuentra en el interior y no en el exterior[1].

En este artículo se describe el traslado de dos pacientes desde Rapa Nui, con alta sospecha imagenológica de COVID -19 al continente, dentro de cápsulas de aislamiento a presión negativa durante una operación de vuelo de 8 horas en constante atención y monitorización médica.

\section{Reporte de casos clínicos}

Se trata de dos pacientes, el primero caso, sexo masculino, edad 24 años, con antecedentes de asma bronquial sin adherencia a tratamiento, y con alta sospecha imagenológica de COVID - 19. Consulta en servicio de urgencias de Hospital de Hanga Roa, por cuadro de 3 días de evolución caracterizado por tos seca asociado a sensación febril cuantificada en 39 ${ }^{\circ} \mathrm{C}$, y acompañado de mialgias generalizadas, coriza, tope inspiratorio, disnea progresiva y compromiso del estado general. Destacando al examen pulmonar patrón obstructivo bilateral y crépitos en base derecha, con saturación de $92 \%$ a $\mathrm{FIO}_{2}$ ambiental. Exámenes muestran recuento de leucocitos de $15.800 / \mathrm{mm}^{3}$, linfocitos $13,3 \%$ y PCR de $2 \mathrm{mg} / \mathrm{dl}$, además un TAC de 


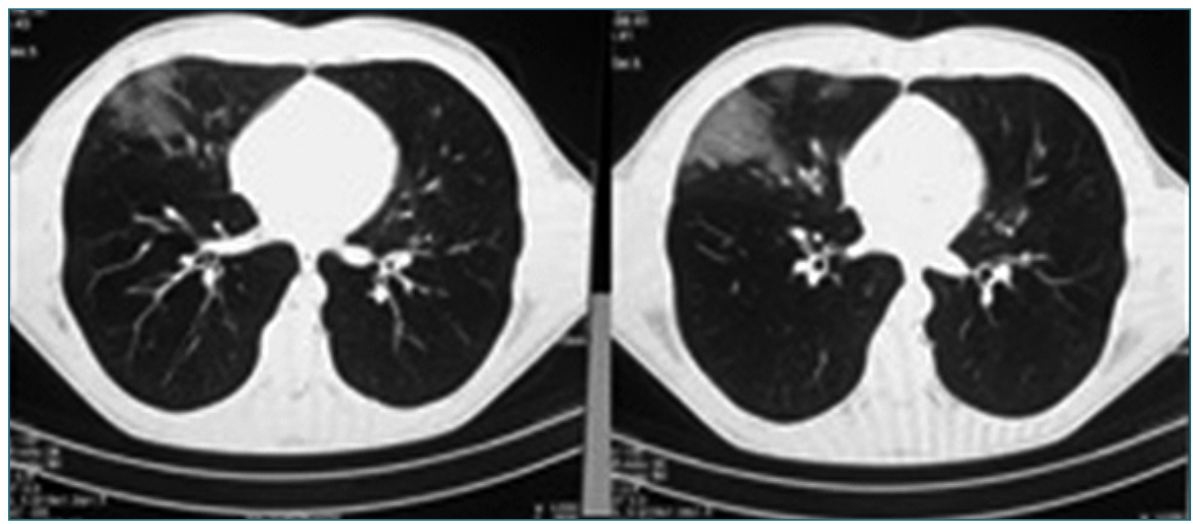

Figura 1. TAC de tórax sin contraste de primer paciente con presencia de opacidades en vidrio esmerilado de lóbulo medio y superior izquierdo.

tórax sin contraste que evidencia presencia de opacidades en vidrio esmerilado de lóbulo medio y superior izquierdo, asociado a banda atelectásica (Figura 1). Se hospitaliza en unidad básica de aislamiento, se inicia tratamiento antibiótico empírico con ceftriaxona y claritromicina, además de terapia broncodilatadora, corticoides sistémicos y oxigenoterapia con mascarilla Venturi con una $\mathrm{FIO}_{2}$ al $40 \%$.

El segundo caso, sexo femenino, edad 45 años, con antecedentes de obesidad grado 2, y con alta sospecha de COVID - 19. Consulta en servicio de urgencias de Hospital de Hanga Roa, por cuadro de tos seca, sensación febril no cuantificada y compromiso del estado general. Destacando al examen pulmonar patrón obstructivo bilateral y crépitos en ambas bases, con saturación de $95 \%$ a $\mathrm{FIO}_{2}$ ambiental. Exámenes muestran recuento de leucocitos de $10.500 / \mathrm{mm}^{3}$, linfocitos $12,8 \%$ y PCR de 2,2 mg/dl, además un TAC de tórax sin contraste que evidencia presencia de opacidades en vidrio esmerilado multisegmentario, asociado a banda atelectásica. Se hospitaliza en unidad básica de aislamiento, se inicia tratamiento antibiótico empírico con tazonam y claritromicina, además de terapia broncodilatadora, corticoides sistémico y oxigenoterapia con naricera. Dada la rapidez con que avanza el compromiso ventilatorio de ambos pacientes, los aumentos de requerimientos de oxígeno que fueron presentando y la ausencia de ventilador mecánico en Rapa Nui, se decide solicitar el traslado aeromédico al continente.

Los elementos de protección personal (EPP) que fueron utilizados por la tripulación aero sanitaria durante el abordaje y traslado de los pacientes fueron traje clínico sanitizado, buzo de seguridad biológica desechable que abarco por completo miembros inferiores, superiores y cabeza, guantes de nitrilo largos hasta el antebrazo, pechera clínica, guantes cortos de nitrilo hasta la muñeca, mascarilla N95, cubre botas clínicas y protector ocular clínico con sistema de antiparras. Los procedimientos de correcta postura y retiro de los EPP fue supervisada en todo momento por personal clínico calificado de la tripulación (Figura 2).

Con el primer paciente debido a que presentaba una PAFI de 140, GSA con evidencia de alcalosis respiratoria en vías de compensación, TAC con presencia de lesión pulmonar aguda y compromiso progresivo ventilatorio, se decidió inducción e intubación de secuencia rápida con un tubo endotraqueal \# 8 , monitorización invasiva de la presión arterial, VVP \# 16 y \# 18 en ambos antebrazos, CVC 3L yugular anterior derecho e instalación de sonda Foley. Una vez intubado e invadido el paciente, se procedió a realizar protocolo de encapsulamiento dispuesto y entrenado por la tripulación aero sanitaria:

- Configuración de la cápsula con instalación de alargadores venosos, corrugados del ventilador, sistemas de monitorización, filtros externos e interno, soplador de presión negativa y ropa de cama, procedimiento realizado por 2 miembros de la tripulación fuera del box de aislamiento.

- Entrada de la cápsula al box de aislamiento adherida a la camilla móvil de la ambulancia, procedimiento realizado por 2 miembros de la tripulación encargados de la intubación e invasión del paciente.

- Traslado del paciente en bloque hacía dentro de la cápsula de aislamiento.

- Configuración del sistema de salida de monitorización.

- Distribución de las vías de administración y respectivos alargadores.

- Chequeo de la correcta instalación de los filtros externos e interno. 


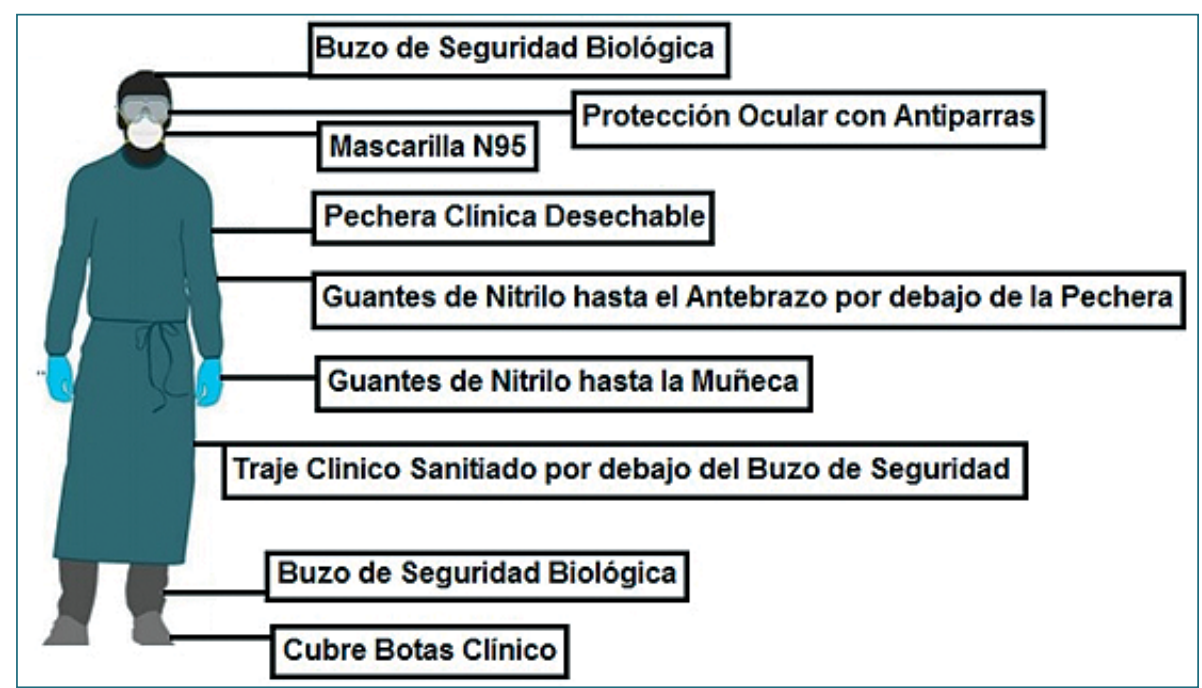

Figura 2. Elementos de protección personal utilizados por la tripulación aero sanitaria.
- Conexión al ventilador mecánico portátil.

- Verificación del confort del paciente, a través de los sistemas de fijación interna y puntos de apoyo.

- Instalación de frazada térmica, pañal y protecciones auditivas al paciente.

Una vez sellado el sistema y efectuado el protocolo de aislamiento se procedió a desinfectar la cápsula por exterior con amonio cuaternario de cuarta generación, por parte de los 2 miembros que se encontraban afuera del box, mientras que los 2 miembros que encapsularon al paciente procedieron al cambio de los EPP supervisados por personal calificado de la tripulación. El segundo paciente que no requirió de ventilación mecánica fue trasladado con monitorización estándar dentro de la cápsula, en ventilación espontánea con una máscara con reservorio a 10 litros/ minuto, utilizando el mismo protocolo de encapsulamiento y realizando los cálculos de requerimientos de oxígeno para asegurar una adecuada saturación durante el vuelo dentro de una aeronave presurizada a 20.000 pies de altitud.

Estas cámaras de aislamiento fueron acopladas mediante un sistema de fijación integrado a las camillas RAVEN 90C del Lockheed Hércules C - 130, permitiendo el funcionamiento del sistema de introducción de material sin alterar la presión del interior, además que cuentan con guantes integrados, lo que permite el manejo desde el exterior[2].

Durante el vuelo de regreso que tuvo una duración de 8 horas, los pacientes se mantuvieron hemodinámicamente estables y sin apoyo de drogas vasoactivas, con una sedación al primer paciente de fentanilo y midazolam por bomba de infusión continua, y bolos de mantención de bromuro de rocuronio cada 60 minutos, con el objetivo terapéutico de mantener una sedación número 6 dentro de la escala de Ramsay[3]. Los parámetros del monitor y ventilador se mantuvieron estables y con un $\mathrm{ETCO}_{2}$ adecuado, cabe mencionar que antes de iniciar el traslado se mantuvo el ventilador con una $\mathrm{FIO}_{2}$ al $100 \%$ y una vez iniciado el vuelo de regreso se mantuvo al $60 \%$. El segundo paciente solo necesito administración de bolos midazolam en 2 oportunidades, además de su oxigenoterapia continua. Ambos pacientes no experimentaron hipoxemia a una altitud de 20.000 pies, que corresponde a la velocidad crucero de la aeronave, debido a que venían con soporte de oxígeno suplementario y dentro de una cabina presurizada.

\section{Discusión}

El beneficio de cualquier traslado aeromédico está limitado por las características de la aeronave, el estado clínico del paciente, la posibilidad de tener acceso para realizar procedimientos médicos durante el trayecto, y la duración de éste[4]. El transporte de pacientes altamente infecciosos es una realidad cada vez más frecuente ante la pandemia actual del COVID - 19, y las condiciones presentes durante un vuelo, como asimismo, los cambios fisiológicos que ahí ocurren, constituyen parámetros que el equipo médico debe conocer y manejar. La Red Europea de Enfermedades Infecciosas (EUNID) ha definido a las Enfermedades Altamente Infecciosas (EAl) como aquellas 
transmisibles de persona a persona causando una enfermedad que amenaza la vida, que representan un riesgo grave y que requieren de medidas de control específicas[5]. En ausencia de un tratamiento definitivo para la mayoría de las EAl, la sospecha e identificación de los casos, el aislamiento inmediato y su posterior traslado, son la norma de referencia mundial para su tratamiento, siempre siguiendo el objetivo de soporte vital adecuado y minimizando el riesgo de transmisión secundaria de la infección[6]. Debe tenerse presente que la evacuación aérea de pacientes con infecciones contagiosas y potencialmente letales, plantea desafíos y riesgos únicos para la tripulación aero sanitaria, situación que ha planteado la necesidad de mantener normas de aislamiento hospitalarios dentro de la aeronave. Para la decisión de transportar un paciente con EAl debe considerarse y programarse de forma adecuada, teniendo en cuenta los protocolos vigentes de los organismos de salud pública y autoridades de la aviación, además de verificar la capacidad de aislamiento de la institución sanitaria que reciba al paciente[7]. Entre los factores a tener en cuenta al tomar la decisión de realizar un traslado médico aéreo se incluye determinar si el paciente está estable para ser evacuado y saber si el personal de atención sanitaria encargado de realizar el traslado está capacitado en el manejo clínico, en fisiología de aviación, control de infecciones y en el uso correcto del elementos de protección personal.

El Hércules C-130 alcanza una velocidad de 700 $\mathrm{Km} /$ hora y una altitud entre los 20.000 a 25.000 pies, está dotado de una cabina presurizada que aplica una presión diferencial mediante la cual se consigue que la altitud efectiva en el interior de la cabina sea del orden de 5.800 a 8.500 pies, en otras palabras, se corrige bastante la altitud de cabina, pero no es la del nivel del mar, debe recordarse que el ser humano, en forma fisiológica, puede sobrevivir normalmente sin aporte de oxígeno suplementario hasta alturas de 10.000 pies. En lo que respecta a la $\mathrm{SaO}_{2}$ la presión atmosférica disminuye en proporción inversa con la altitud, de hecho, la presión de oxígeno inspirado se reduce en $5 \mathrm{~mm}$ de HG por cada 1.000 pies de ascenso, esto implica que a una altitud de 10.000 pies una persona sana y joven tiene una saturación arterial de oxígeno entre 92 a 94\%[8]. Prediciendo la hipoxemia de vuelo se deben hacer algunas afirmaciones, como considerar una caída de la $\mathrm{SaO}_{2}$ de 3 a $4 \%$, y que un paciente con una $\mathrm{paO}_{2}$ de $72 \mathrm{~mm}$ de $\mathrm{HG}$ respirando aire ambiental no requiere de oxígeno suplementario para realizar un vuelo[9], en cambio los enfermos respiratorios pueden experimentar hipoxemia a esa altitud amenazando su estabilidad hemodinámica, debido a que no cuentan con una reserva funcional, y no logran compensar esta caída en la saturación de oxígeno, debido a que presentan alteraciones en el recambio gaseoso, en lo que respecta la difusión y transporte de $\mathrm{O}_{2}$, y mecánica ventilatoria, por lo tanto, se hizo empleo de balones de oxígeno certificados y dispusimos de sistemas adecuados de fijación a la cabina, para descartar situaciones altamente riesgosas y restringidas. Debido a la Ley de Boyle, que dice que las cámaras gaseosas se expanden ante la disminución de la presión ambiental se emplearon suero en bolsas sintéticas colapsables sin cámara de aire, y en el volumen de los cuff traqueales, así la presión ejercida para para sellar la vía aérea no fue necesaria ajustarla una vez alcanzada la altitud de crucero.

El brote epidémico por virus Ébola ocurrido en África durante el año 2014, con amenaza de transformarse en pandemia, revelo algunas preguntas respecto al traslado o evacuación de personas altamente expuestas o infectadas, por otra parte, debido al aumento de la aviación a nivel mundial, en cuanto al número de vuelos, personas transportadas y las distancias alcanzadas, ha constituido un riesgo potencial de contagio y diseminación de enfermedades infecciosas por todo el planeta[10]. La contención biológica se diseñó para evitar la transmisión de patógenos realizándose en dos etapas, la primera etapa corresponde a los elementos de protección personal (EPP) de la tripulación aero sanitaria, y la segunda considera que el paciente debe ser aislado dentro de un contenedor sellado de presión negativa de aire que se mantiene por un sistema de ventilación con filtros, y es capaz de proporcionar cinco cambios de aire por hora[11].

Las capsulas de aislamiento cumplieron un rol fundamental durante el traslado, estas cámaras están confeccionadas por plástico altamente resistente y transparente que permitió visualizar al interior, y también permitieron al paciente no ventilado ver el exterior, con lo que se puede reducir notablemente el nivel de ansiedad. Se pudieron acoplar diferentes tipos de filtros, mecánicos de membrana con una eficacia de retención de 99,5\% contra aerosoles sólidos, y HEPA (High Efficiency Particulate Air) con una eficacia de retención de 99,7\% para partículas de 0,3 $\mu \mathrm{m}$ o mayores[12]. Por esta razón, el aire es filtrado a la salida, mientras que en los dispositivos de aislamiento a presión atmosférica el aire que entra es filtrado[13]. Estos módulos disponen de una estructura rígida que impide el colapso cuando está activado el sistema de presión negativa, que se obtiene con una o varias unidades monitorizadas que extraen aire del interior y lo pasan por un filtro para que el aire salga limpio de 


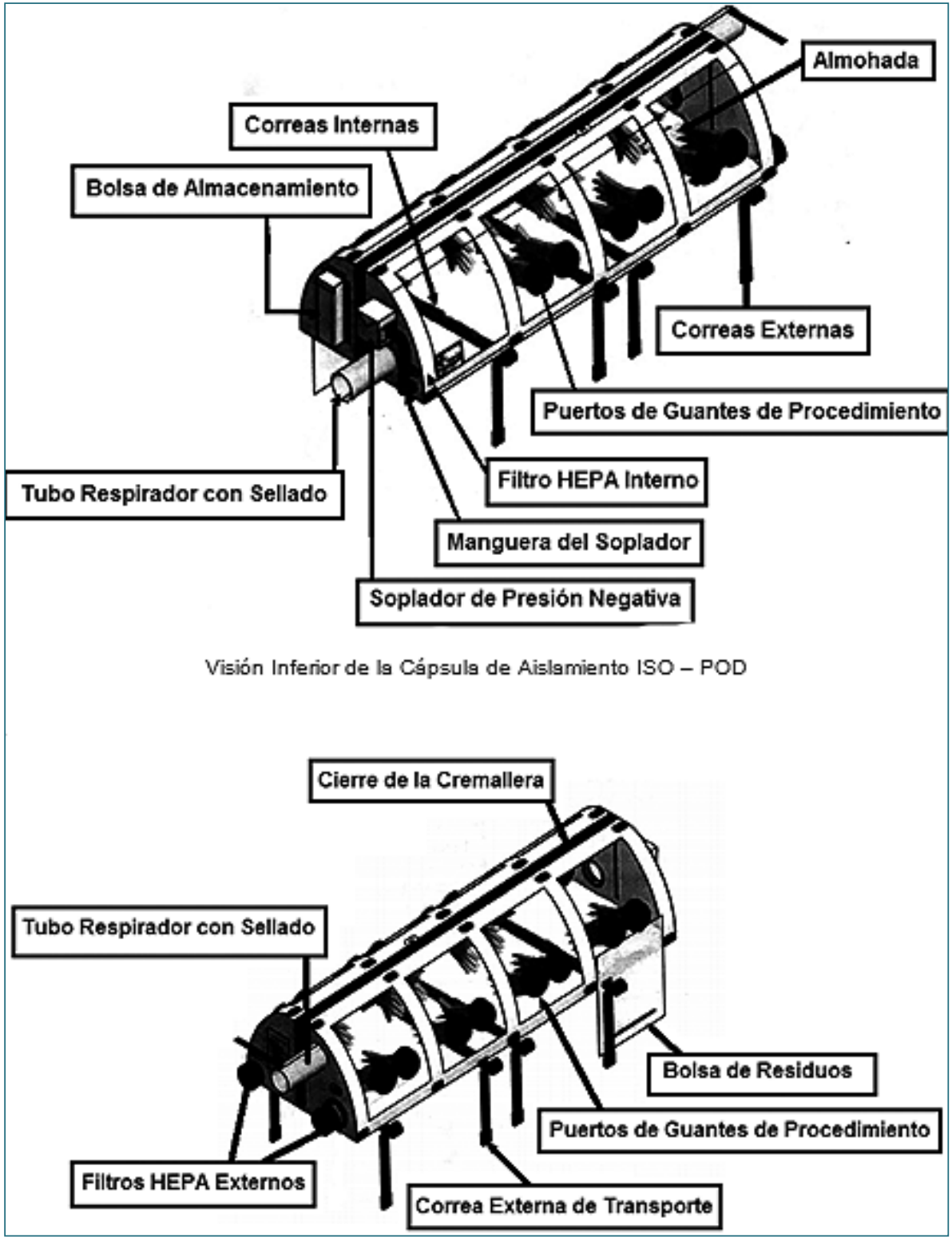

Figura 3. Cápsulas de aislamiento con soporte vital avanzado (ISO - POD).

contaminación, funcionan de forma autónoma con baterías o se conectan a la fuente de alimentación de la aeronave[14] (Figura 3).

La recomendación internacional considera el uso de unidades de aislamiento portátiles para la gestión de los cuidados durante el traslado del paciente altamente infeccioso y, asimismo, la provisión de contenedores seguros para almacenar residuos contaminados con agentes biológicos, de tal manera de evitar la extensión de la contaminación hacía la aeronave[15], protocolos estandarizados y supervisados por el personal sanitario a bordo. Es de vital importancia señalar que los pacientes fueron evacuados en las cápsulas de aislamiento a presión negativa hasta el centro de salud de destino, y fueron ascendidos y descendidos de la aeronave con los motores apagados, bajo los protocolos de seguridad de la tripulación.

El procedimiento se realizó con un equipamiento 
médico certificado para su uso en vuelo, lo que significó trabajar con un ventilador mecánico que ciclara estable en presión y volumen a distintas alturas, además de ventilar con distintos porcentajes de oxígeno, monitores multiparámetros que no interfieran con los campos electromagnéticos o equipos electrónicos de la aeronave, que sean compatibles con actividades de vuelo nocturnas, y baterías de repuesto ante cualquier imprevisto. Las bombas de infusión continua utilizadas durante el vuelo, fueron pequeñas y con baterías de larga duración, además que constaban con el software de $\mathrm{TCl}$ para administrar diferentes medicamentos, además se contó con una cámara de aislamiento de respaldo.

Dentro de las variables que nos condicionaron la evacuación fueron:

- Espacio Reducido.

- Vibración y Ruido de la Aeronave.

- Dificultad de la Comunicación del Equipo.

- Fuerza de Gravedad y la Aceleración.

El interior de la cabina represento un reto para la tripulación aero sanitaria, dado que el espacio fue limitado e impidió la libre deambulación y acceso al paciente. El ruido hizo no escuchar el ruido de las alarmas, por lo que se tuvo que estar alerta ante las alarmas visuales de los diferentes equipos, especialmente del ventilador mecánico, las vibraciones no interfirieron en la señal de los monitores y en el cuentagotas de las bombas de infusión continua, por lo que, no fue necesario ser reprogramados periódicamente. El aire presente en el interior de la aeronave es un aire seco que contiene una humedad cercana al 10\%, lo que ocasiono irritación cutánea y molestias oculares a la tripulación aero sanitaria, que sumado a los EPP dificultaba aún más el trabajo médico. En lo que respecta a la fuerza de gravedad y aceleración, estas fueron consideradas durante el despegue y aterrizaje, y no fue de mayor importancia durante el vuelo. El comportamiento de la temperatura, mejor conocido por la Gradiente Térmica Vertical, corresponde a una razón lineal de disminución de la temperatura ambiental de $2^{\circ} \mathrm{C}$ por cada 1.000 pies de ascenso, hecho que no ocurrió con nuestros pacientes, los cuales fueron evacuados con kit de hipotermia y monitoreo constante de la temperatura a nivel axilar, además se constato que los mayores requerimientos de sedoanalgesia al paciente ventilado ocurrieron durante el traslado de la cápsula a la ambulancia, de la ambulancia a la aeronave y durante las primeras 3 horas de vuelo.

En relación a las zonas dentro de la aeronave se establecieron 3 zonas de seguridad, la zona limpia donde se encontraba la tripulación de vuelo, una zona intermedia donde se encontraba la zona de REAS (Residuos de Establecimientos de Atención de Salud), donde se eliminaban los residuos de peligro biológico y la zona sanitaria o de los pacientes, con sus respectivas cápsulas de aislamiento[16]. El movimiento de la tripulación, dentro de las zonas establecidas en el avión, se realizó bajo un protocolo y fue supervisado en todo momento por personal médico calificado (Figura 4).

La tripulación aero sanitaria estuvo conformada

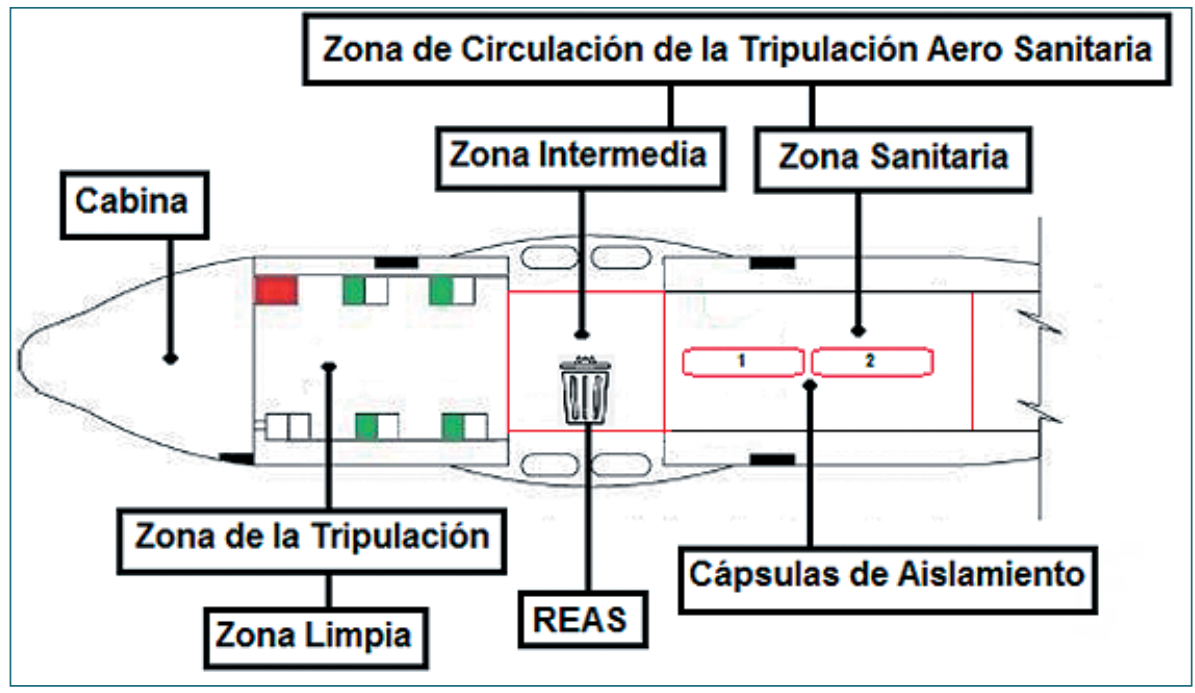

Figura 4. Distribución de zonas en el Hércules C - 130 durante el traslado aero médico. 

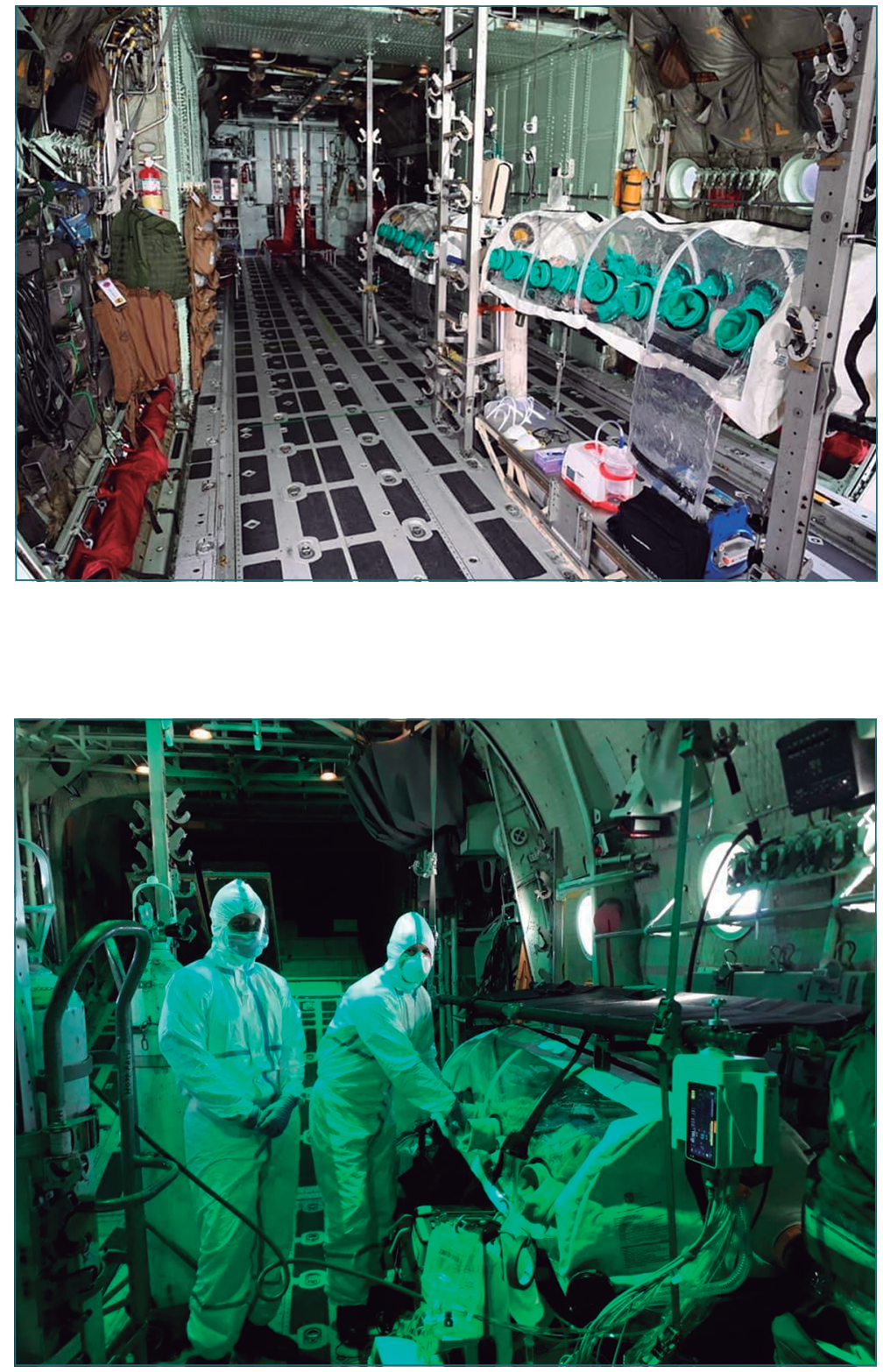

Figura 5. Distribución de las cápsulas de aislamiento en Hércules C-130.
Figura 6. Elementos de protección personal utilizados por la tripulación aero sanitaria. por dos médicos anestesiólogos institucionales, 2 enfermeros universitarios y 2 enfermeros de combate con experiencia en cuidados intensivos, que fueron entrenados bajo un sistema de planificación para evitar la deshidratación y fatiga durante el vuelo, y así disminuir la posibilidad de error y el riesgo de infección a la tripulación de la aeronave.

Este artículo busca entregar a la comunidad médica una experiencia de rescate y transporte aéreo médico, a través de una experiencia satisfactoria por medio de cámaras de aislamiento a presión negativa con soporte con vital avanzado. Contar con un equipo aero médico con un alto grado de profesionalismo y compromiso, es indispensable para la seguridad de la salud de todos los chilenos ante la pandemia actual del COVID - 19. 


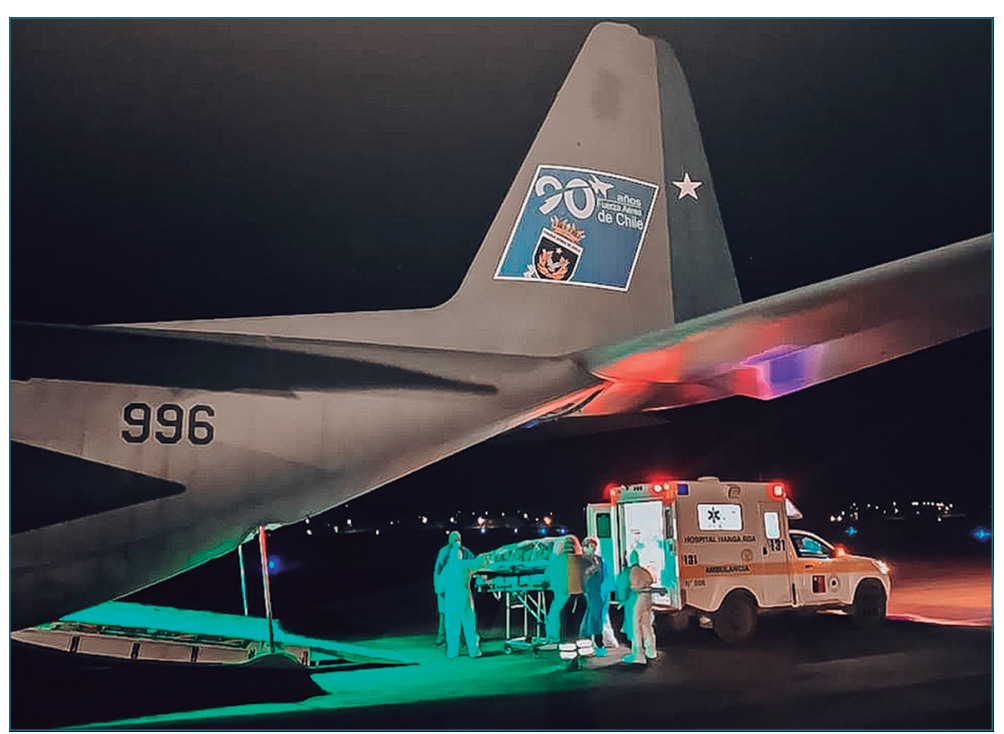

Figura 7. Traslado de Pacientes desde Hércules C - 130 a Ambulancia Grupo $\mathrm{N}^{\circ} 10$ de la FACH.

\section{Referencias}

1. Worster, A, Bledsoe, RD, Cleve, $P$, Fernandes, CM, Upadhye, $S$, Eva, K. Reassessing the methods of medical record review studies in emergency medicine research. Ann Emerg Med. 2005;45(4):448-451.

2. Sand M, Bechara FG, Sand D, Mann B. Surgical andmedical emergencies on board European aircraft: aretrospective study of 10189 cases. Crit Care 2009; 13:R3.5.

3. Ramsay MAE. Intensive care: problems of over-and undersedation. Baillieres Clin Anaesthesiol. 2000;14:419-32.

4. Tran, Khai, Karen Cimon, Melissa Severn, Carmem L. Pessoa-Silva, and John Conly. 2012. "Aerosol Generating Procedures and Risk of Transmission of Acute Respiratory Infections to Healthcare Workers: A Systematic Review." PloS One 7 (4): e35797.
5. World Health Organization (WHO). Global Surveillance for Human Infection with Coronavirus Disease (COVID19). WHO, 2020.

6. World Health Organization (WHO). How to Put On and Take Off Personal Protective Equipment (PPE). WHO, 2020.

7. World Health Organization (WHO). Natural Ventilation for Infection Control in Health Care Settings. Geneva, WHO, 2020

8. Public Health England. COVID-19: Guidance for Ambulance Trusts. PHE, 2020.

9. Centers for Disease Control and Prevention. Interim Guidance for Emergency Medical Services (EMS) Systems and 911 Public Safety Answering Points (PSAPs) for COVID-19 in the United States. CDC, 2020.

10. World Health Organization. Global Surveillance for human infection with coronavirus disease (COVID-2019). Interim Guidance
(2020) WHO 2020. Geneve.

11. World Health Organization. Decontamination and Reprocessing of Medical Devices for Healthcare Facilities. WHO, 2016.

12. World Health Organization. Q\&A on Infection Prevention and Control for Health Care Workers Caring for Patients with Suspected or Confirmed 2019-nCoV. WHO, 2020.

13. Office of the Assistant Secretary for Preparedness and Response (ASPR). COVID-19 Healthcare Planning Checklist. ASPR, 2020.

14. Centers for Disease Control and Prevention. Coronavirus Disease 2019: How to Prepare - Manage Anxiety \& Stress. CDC, 2020.

15. Organización Mundial de la Salud. Reglamento Sanitario Internacional Tercera edición (2005) OMS 2005. 104 pp.

16. World Health Organization. Global Surveillance for human infection with coronavirus disease (COVID-2019). Interim Guidance (2020) WHO 2020. Geneve. 